\title{
(t)
}

\section{O NEXO NECESSÁRIO E VITAL: IDEOLOGIA E HISTÓRIA EM KARL MARX}

\author{
THE NECESSARY AND VITAL NEXUS: IDEOLOGY \\ AND HISTORY IN KARL MARX
}

\section{Adilson Aquino Silveira Júnior ${ }^{1}$}

\section{RESUMO}

Este texto visa apreender as determinações teórico-metodológicas fornecidas pela obra de Karl Marx para a análise das relações entre as dimensões econômicas e ideológicas da reprodução social e, especificamente, do ordenamento social matizado pelas contradições classistas. Foram utilizados como fontes bibliográficas os textos marxianos, elaborados em diversos momentos da vida intelectual do autor, além das sínteses e interpretações de pensadores que apreenderam e desenvolveram, positiva e criativamente, a perspectiva de Marx, tais como Georg Lukács, Antônio Gramsci e István Mészáros.

Palavras-chave: Estrutura social. Ideologia. Método.

\section{ABSTRACT}

The article aims to apprehend the theoretical-methodological determinations provided by the work of Karl Marx for the analysis of the relationships between economic and ideological dimensions of social reproduction and, specifically, of the social order based on classist contradictions. In this study, were used as bibliographical sources marxian texts, elaborated in different moments of the intellectual life of this author, besides the syntheses and interpretations of thinkers who seized and developed, positively and creatively, Marx's perspective, such as Georg Lukács, Antônio Gramsci and István Mészáros.

Keywords: Social structure. Ideology. Method.

Submetido em 21/07/2013

Aceito em 20/12/2013

1 Mestre e Doutorando em Serviço Social pela Universidade Federal de Pernambuco (UFPE). E-mail: j_r1987@hotmail.com. 


\section{INTRODUÇÃO}

Este trabalho busca determinar as contribuições teórico-metodológicas fornecidas pela obra de Karl Marx para a análise das relações entre os aspectos material e espírito-intelectual (os complexos ideológicos) da reprodução social e, especificamente, do ordenamento social estruturado pelas contradições de classe. Tal estudo torna-se pertinente, sobretudo, pela vulgarização de que é objeto a perspectiva marxiana em amplos segmentos das ciências sociais, recorrentemente tratada como uma abordagem unilateral, pretensamente eivada por um reducionismo econômico na explicação das relações sociais. Frequentemente, tais abordagens são erigidas sem um estudo sistemático que recorra aos próprios termos do autor em análise. Desse modo, para a realização da investigação, foram utilizadas fontes bibliográficas referentes aos textos marxianos, elaborados em diversos momentos da vida intelectual do autor. Além disso, foram utilizadas as sínteses analíticas de estudiosos que apreenderam e desenvolveram, positiva e criativamente, a perspectiva de Marx, tais como Georg Lukács, Antônio Gramsci e István Mészáros.

\section{O PODER DA IDEOLOGIA}

Antes de avançarmos nas relações entre estrutura social e história em Marx, devemos tratar da categoria da ideologia, porquanto a explicitação prévia desta é fundamental para tornar inteligível toda a concepção em tela. A questão da ideologia na obra marxiana é alvo de controversas importantes, e os debates que buscam elaborar uma interpretação unívoca em relação a ela espraiam-se até os dias atuais². Não obstante a conhecida identificação entre ideologia e "falsa consciência", a partir da análise dos próprios textos de Marx, assumimos como referência outra interpretação fornecida (de modo convergente) por Gramsci, Lukács e Mészáros para a apreensão das formas ideológicas na abordagem marxiana. Esses autores as entendem não apenas com base em uma perspectiva gnosiológica (verdadeira ou falsa elaboração

2 No Brasil, há algumas obras de referência que tratam da questão da ideologia, tanto no que se refere aos seus significados no interior de diversas tradições teóricas quanto, especificamente, na tradição marxista, como é o caso de Konder (2002), Chauí (1980) e Löwi (2000). Outras duas obras traduzidas nos fornecem esse panorama mais geral: Eagleton (1997) e Zizek (1996). 
do real), mas como um tipo de consciência social específico das sociedades de classe, cuja função consiste na conscientização e no embate dos conflitos lançados pelo desenvolvimento econô$\mathrm{mico}^{3}$. A referência principal para esse tratamento diz respeito a um trecho do Prefácio à Contribuição à crítica da economia política, que trata da seguinte assertiva para a compreensão das épocas de revolução social proporcionadas pela contradição entre o desenvolvimento das forças produtivas e as relações de produção:

Quando se considera tais transformações [das superestruturas, provocadas pela base econômica] convém distinguir sempre a transformação material das condições econômicas de produção [...] e as formas jurídicas, políticas, religiosas, artísticas ou filosóficas, em resumo, as formas ideológicas, sob as quais os homens adquirem consciência desse conflito e o levam até o fim (MARX, 2008a, p. 46)4.

Na síntese de Mészáros (2008, 2004), ao articular sua visão de ordem social correta e apropriada como um todo abrangente, as ideologias em luta, em qualquer período histórico, constituem a consciência prática necessária, através da qual as mais importantes classes da sociedade se relacionam e, de certa forma, até mesmo se confrontam abertamente. Destarte, a luta estratégica mais importante em termos estruturais - cujo objetivo consiste em preservar ou, ao contrário, superar o sociometabolismo dominante - encontra suas manifestações necessárias nas "formas ideológicas" orientadas para a prática social, a partir das quais os homens se tornam conscientes desse conflito social e o resolvem através da luta (MARX, 2008a). O que determina a natureza da ideologia é, portanto, o imperativo de tornar "consciente em termos práticos" o conflito social fundamental - a partir dos pontos

3 Coutinho (2011) sinaliza legitimamente para essa convergência entre Gramsci e Lukács, no que concerne ao entendimento da questão da ideologia em Marx. Para o autor, ambos insistem no caráter ontológico-social da ideologia e vinculam-na de modo explícito à práxis política enquanto ação interativa.

4 Para Lukács (2010), essa determinação abrangente de Marx não fornece nenhuma resposta unívoca à questão de correção ou falsidade metodológica e objetiva das ideologias, ambas são igualmente possíveis na prática. Assim, pois, as ideologias podem proporcionar tanto uma aproximação do ser como um afastamento dele. 
de vista mutuamente excludentes das alternativas hegemônicas que se defrontam em determinada ordem social -, com o propósito de "resolvê-lo através da luta" (MARX, 2008a, p. 46). As próprias elaborações gramscianas e lukacsianas indicam-nos que as diversas formas ideológicas de consciência social acarretam, em graus variáveis, direta ou indiretamente, diversas implicações práticas na arte e na literatura, bem como na filosofia e na teoria social, não obstante a sua ancoragem sociopolítica em posições progressistas ou conservadoras.

Em Prolegômenos para uma ontologia do ser social, Lukács (2010) apresenta algumas determinações importantes para compreendermos a função dos complexos ideológicos no metabolismo social, sobretudo no que concerne à relação entre indivíduo e gênero. É preciso ratificar que, para esse autor, a correção ou a falsidade não bastam para fazer de uma opinião uma ideologia; muito menos uma opinião individual correta ou errônea é em si e por si uma ideologia: pode, apenas, vir a ser. Seguindo a concepção marxiana, Lukács (2010) afirma que somente após se tornarem veículo teórico ou prático para combater conflitos sociais, quaisquer que sejam - grandes ou pequenos, episódicos ou decisivos para o destino da sociedade -, elas passam a ser ideologia. Sua análise parte da determinação da ideologia como veículo de conscientização e prévia-ideação da prática social dos homens: "[...] a ideologia é antes de tudo uma forma de elaboração ideal da realidade que serve para tornar a práxis social dos homens consciente e operativa" (LUKÁCS, 2010, p. 446)5. Para o filósofo húngaro, a ideologia - em última análise - possui o papel de ordenar as decisões isoladas dos indivíduos sociais em um contexto de vida geral dos seres humanos e esforça-se por esclarecer ao indivíduo como é indispensável para sua própria existência avaliar as decisões segundo os interesses coletivos (ou dominantes, no caso das formações classistas) da sociedade. Destarte, as ideologias importam, porquanto assumem a condição de mediação da

5 Portanto, "[...] na medida em que o ser social exerce uma determinação sobre todas as manifestações e expressões humanas, qualquer reação, ou seja, qualquer resposta que os homens venham a formular, em relação aos problemas postos pelo seu ambiente econômico-social, pode, ao orientar a prática social, ao conscientizá-la e operacionalizá-la, tornar-se ideologia" (VAISMAN, 2010, p. 418). 
reprodução social, dirigindo as vontades humanas, através da formação de uma determinada consciência social, para resultar em efeitos práticos específicos na sociedade, correspondentes aos interesses socioeconômicos concretos em presença. $O$ valor histórico das superestruturas evidencia o "nexo necessário e vital" (GRAMSCl, 2011) destas com a estrutura social e sua capacidade concreta de agir retroativamente no sociometabolismo, seja para a preservação das relações sociais estabelecidas, seja para sua superação por uma dinâmica sociometabólica alternativa.

\section{CONSCIÊNCIA SOCIAL ENQUANTO HISTORICIDADE}

Não são poucos os analistas que injustamente acusam Marx de abordar as formas de consciência social, ou seja, as ideologias, como um subproduto ou epifenômeno da estrutura econômica capitalista. Nesses termos, as superestruturas jurídico-políticas e as próprias ideologias - seriam uma decorrência direta e imediata dos interesses absolutos do capital, o que resultaria na impostação de cadeias estruturais intransponíveis para a formação de ideologias alternativas (contra-hegemônicas) no interior das relações sociais matizadas pelo metabolismo burguês. $\mathrm{O}$ evidente equívoco dessas investidas consiste, em parte, no fato de que, para Marx, o capital é uma relação sócio-histórica inerentemente contraditória, que reproduz de modo ampliado seu polo oposto, a classe do trabalho. Este carrega, inerentemente, a possibilidade de colocar como problema para o conhecimento consciente as causas das condições de vida que lhe são impostas. Por mais profundos que sejam os processos de reificação, a classe do trabalho constitui sempre um sujeito histórico, portador de uma subjetividade, que pode responder alternativamente aos problemas colocados pela reprodução social antagonista. Sem a apreensão teórica da relação-capital nesses termos concretos sob os quais se apresenta no movimento histórico, a própria possibilidade da revolução estaria inviabilizada. Ou seja, precisamente, o movimento prático determinado para o qual Marx orientava todas as suas forças intelectuais não poderia se tornar real, sem mencionar que a própria existência de uma concepção de mundo própria dos trabalhadores não poderia se efetivar. 
$\mathrm{Na}$ polêmica com os novos hegelianos de esquerda da Alemanha, por vezes, Marx precisou sublinhar a determinação do momento predominante das condições históricas necessárias para que se tornasse viável a realização de qualquer mudança social. Marx e Engels (2003, p. 15), no Prólogo de A Sagrada Família, de 1845, afirmam: "O que combatemos na Crítica baueriana é justamente a especulação que se reproduz à maneira de caricatura". O problema, de natureza não apenas teórica, mas também político-ideológica, é que os opositores posteriores de Marx (e da tradição marxista) sustentam inapropriadamente interpretações dessa abordagem, colocando-a no lado oposto da argumentação. Ou seja, de acordo com os intelectuais que recusam, abandonam ou intentam superar essa tradição, Marx (e Engels) teria assumido o materialismo ou economicismo na mesma medida em que Bruno Bauer e consortes teriam incorporado o idealismo: "à maneira de caricatura"; nada mais distante da complexidade da abordagem ontológica e, portanto, dialética de Marx. Em A Sagrada Família, o inimigo do "humanismo real" de Marx e Engels consistia precisamente no "idealismo especulativo" que colocava a "autoconsciência" ou o "espírito" no lugar do "ser humano individual e verdadeiro", tentando "transformar a crítica em si numa força transcendental” (MARX; ENGELS, 2003, p. 15).

É certo que em diferentes momentos Marx e Engels (2007, p. 29) haviam argumentado, em A ideologia alemã, de 1846, que “[...] a 'libertação' é um ato histórico e não um ato de pensamento, e é ocasionada por condições históricas"; ou, no Prefácio à Crítica da economia política, de 1859, que não é a "consciência dos homens que determina o ser; ao contrário, é o ser social que determina sua consciência" (MARX, 2008a, p. 45). Porém, nesses casos, estariam isentas das "condições históricas", ou da constituição do "ser social", as formas de consciência ou as modalidades de ideologia? Distante disso. Mészáros (2008) mostra que Marx define as "condições objetivas" de uma ruptura revolucionária em termos da determinação recíproca do ser social e da consciência social. Portanto, mesmo no combate impenitente e no acerto de contas com a posição idealista especulativa, levados a cabo com uma ironia fina, em A Sagrada Família, não resulta 
numa orientação materialista vulgar ou num determinismo estreito dos fatores econômicos. Seus autores destacam reiteradamente a necessidade das condições objetivas, em conexão com uma intervenção consciente do proletariado, para a superação da ordem burguesa. Demais, no mesmo manuscrito de 1846, no qual Marx e Engels afirmam: "Não é a consciência que determina a vida, mas a vida que determina a consciência", encontramos destacado também que "[...] a consciência não pode jamais ser outra coisa do que o ser consciente, e o ser dos homens é o seu processo de vida real" (MARX; ENGELS, 2007, p. 94). Em suma, a perspectiva de crítica ontológica marxiana está sinalizando, tão somente, que não podem existir ideias determinadas, no vazio, sem seres sociais conscientes em dadas condições históricas para elaborá-las e expressá-las. "A existência de ideias revolucionárias numa determinada época pressupõe desde já a existência de uma classe revolucionária" (MARX; ENGELS, 2007, p. 48).

Como é evidente, Marx não somente chamava a atenção para o poder das ideologias no desenvolvimento histórico, como também insistia na necessidade da formação de um movimento consciente dos trabalhadores como momento incontornável no próprio processo revolucionário. Em outros termos, nosso autor nunca abandonou a exigência da formação, por parte dos próprios trabalhadores, de uma consciência classista unitária, crítica, autônoma e de massas como momento necessário da superação do capital e da construção de uma sociedade comunista. De fato, ainda em A ideologia alemã, Marx e Engels (2007, p. 43) afirmam que os "elementos materiais de uma subversão total" são, sobretudo, "[...] de um lado, as forças produtivas existentes e, de outro, a formação de uma massa revolucionária que revolucione não apenas as condições particulares da sociedade até então existente, como também a própria 'produção da vida' que ainda vigora - a 'atividade total' na qual a sociedade se baseia [...]".

Para os autores desse manuscrito, se tais condições são inexistentes, não importa "[...] se a ideia dessa subversão total já foi proclamada uma centena de vezes [...]" (MARX, ENGELS, 2007, p. 43). Sem as forças materiais, as ideologias convertem-se em "fantasias individuais", "ideologias arbitrárias", nos termos de Gramsci (2011). Seguindo os pressupostos marxianos, torna-se 
imprescindível - em articulação com as condições materiais postas pelas forças produtivas - a criação em massa de uma consciência comunista - enquanto consciência da necessidade de uma revolução radical - por parte da classe do trabalho, realizada através do próprio movimento prático. Nesse momento, tanto os homens (em escala "massiva") quanto as circunstâncias devem passar por um processo de transformação altamente complexo. Com efeito, Mészáros (2009, p. 1041) afirma que desde seus primeiros escritos até Grundrisse e 0 capital Marx insistiu "[...] na necessidade da formação de uma consciência de massa socialista, como exigência sine qua non para envolver a maioria dos indivíduos em seu empreendimento coletivo de autoemancipação". No livro primeiro de 0 capital, único volume da monumental e inacabada "obra econômica", preparado para publicação com o autor em vida, podemos observar que a superação do fetichismo, enquanto processo de alienação próprio da sociedade burguesa, encontra-se vinculada não apenas àquela forma de produção material fundada na "comunidade dos produtores livremente associados", mas também à realização do "controle consciente e planejado" destes sobre a produção da riqueza nessa nova base social (MARX, 2008b, p. 101).

Vimos que essa posição é assumida por Marx desde os anos 1840, como fica patente na referência de A ideologia Alemã. Na consideração dos processos reais de lutas de classes na Europa de seu tempo, o autor ressaltava a importância do momento "teórico" do proletariado do continente, da apreensão consciente do movimento concreto da sociedade pela massa revolucionária, como mediação que poderia fornecer um caráter qualitativamente superior à sua revolta. No texto de julho de 1844 , intitulado "Glosas críticas ao artigo 'O rei da Prússia e a reforma social'. De um prussiano”, o recém-iniciado levante dos tecelões da Silésia (Alemanha), em junho do mesmo ano, é considerado "superior" àqueles até então ocorridos na França e na Inglaterra, precisamente por seu caráter "teórico" e "consciente". Esse caráter superior era constatado na atividade prática do próprio

6 Para conferir informações sobre o plano estrutural da principal obra econômica de Marx, de 1857, e suas modificações, ver Rosdolsky (2001). 
movimento, dirigido por uma práxis consciente do dinamismo, não apenas aparente, mas também oculto da produção:

Não são destruídas apenas máquinas, essas rivais
dos trabalhadores, mas também os livros contábeis,
os títulos de propriedade, e, ao passo que todos os
demais movimentos se voltavam apenas contra o
industrial, inimigo visível, esse movimento se vol-
tou simultaneamente contra o banqueiro, o inimigo
oculto (MARX, 2010a, p. 44).

Esse trecho explicita como a ênfase no poder material das formas de consciência diferenciava-se substancialmente do idealismo especulativo que foi objeto da crítica marxiana nos primeiros anos da década de 1840. No interior do próprio evolver econômico-político inerentemente dialético da propriedade privada, encontra-se a reprodução contraditória da antítese que pode levá-la à dissolução: o proletariado como "partido destruidor" da ordem imperante. Entretanto, essa assertiva é admitida cum grano salis. A dinâmica da propriedade privada que impulsiona si mesma à sua própria dissolução efetiva-se não através de um espontaneismo imediato, mas apenas “[...] enquanto engendra o proletariado enquanto proletariado, enquanto engendra a miséria consciente de sua miséria espiritual e física, enquanto engendra a desumanização consciente - e, portanto, suprassunsora - de sua própria desumanização" (MARX; ENGELS, 2003, p. 48). Como Marx verificou no levante dos tecelões da Silésia, o movimento prático consciente do conjunto das relações sociais que constituem o metabolismo burguês se expressa numa práxis política qualitativamente superior em face das lutas de classes. Tal práxis superior demanda a elaboração científica e filosófica, a luta ideológica e a atividade hegemônica da classe proletária e seus "teóricos", ou seja, o desenvolvimento das "armas espirituais" e da dimensão teórica da atividade da classe revolucionária enquanto momento "determinante determinado" de sua iniciativa histórica de autoemancipação.

Como vimos, as modalidades de ideologia que conformam a atividade humana em cada caso não derivam do "ventre da ideia que se põe a si mesma" (MARX, 2011, p. 217), tampouco são “"autodeterminações' do conceito que se desenvolve na história” 
(MARX; ENGELS, 2007, p. 49). As ideologias são erigidas no interior no metabolismo social e possuem importância ou ponderação histórica na medida em que se constituem mediações da práxis humana concreta e se expressam nos modos de agir existentes nas forças sociais em presença. Tal perspectiva foi sintetizada em finais de 1843, na conhecida passagem da Crítica da filosofia do direito de Hegel - Introdução, na qual Marx (2010b, p. 151) afirma: “A arma da crítica não pode, é claro, substituir a crítica das armas, o poder material tem de ser derrubado pelo poder material, mas a teoria também se torna força material quando se apodera das massas".

\section{A PERSPECTIVA TEÓRICO-METODOLÓGICA MARXIANA}

Precisamos considerar, portanto, a complexidade da metodologia dialética que envolve a abordagem marxiana sobre a ideologia, enquanto forma específica de consciência social operante no sociometabolismo - ontologicamente determinada pela categoria fundante do ser social, o trabalho. Mais especificamente, é necessário aprofundar como Marx apreendeu e investigou a qualidade das interações entre os aspectos material e espírito-intelectual da reprodução social e, especificamente, do ordenamento social estruturado pelas contradições de classe. Recorreremos aqui às sínteses analíticas de autores que apreenderam e desenvolveram, positiva e criativamente, a perspectiva marxiana, sem prejuízo das referências às fontes.

Mészáros (2008) afirma que, embora os fundamentos econômicos da sociedade capitalista constituam em Marx os "determinantes fundamentais" do ser social das classes sociais, eles são igualmente, e de forma concomitante, "determinantes determinados". Assim, os apontamentos sobre o significado ontológico da economia apenas adquirem sentido considerando a capacidade de apreendermos as "interações complexas" entre os mais variados campos da atividade humana, ou seja, da práxis social. As diversificadas manifestações institucionais e espírito-intelectuais da vida social não se revelam simplesmente "construídas sobre" uma base econômica, mas também "estruturam ativamente" essa base, através de seu estatuto próprio, imensamente intricado e relativamente autônomo. Segundo o autor, as 
determinações econômicas não existem fora do complexo historicamente mutável de mediações sociais específicas. Portanto, a consciência social, nas suas mediadas formas e manifestações, possui uma estrutura própria "relativamente autônoma", determinando, de forma recíproca, as estruturas econômicas da sociedade, ao mesmo tempo que é determinada por elas. Nessa perspectiva, nenhum dos aspectos econômicos é inteligível na ausência da categoria historicamente mutável das "necessidades humanas", impossível de ser explicada, de maneira plausível, em termos de determinações econômicas unilaterais.

Em sua crítica a Feuerbach, Marx e Engels (2007, p. 31) expunham coerentemente (embora ainda em um estágio inicial das investigações no campo da economia política) sua metodologia da análise histórica: “A indústria e o comércio, a produção e o intercâmbio das necessidades vitais condicionam, por seu lado, a distribuição, a estrutura das diferentes classes sociais e são, por sua vez, condicionadas por elas no modo de seu funcionamento". Tal abordagem consiste na apreensão e determinação da totalidade dinamizada e historicamente determinada pela interação recíproca entre os seus diferentes "aspectos" (ou complexos) constituintes. O ponto de partida é a análise do momento fundante da sociabilidade (a produção material imediata e historicamente situada) e sua conexão com a "forma de intercâmbio" por ele engendrada - que Marx e Engels (2007) identificam como a "sociedade civil" em seus diferentes estágios e apresentam seu modo de operação como "Estado". A partir dessa análise, devemos apreender o conjunto das diferentes criações teóricas e as formas de consciência, na condição de dimensão constitutiva do ser social apresentado em sua historicidade.

A produção das ideias, de representações, da consciência, está, em princípio, imediatamente entrelaçada com a atividade material e com o intercâmbio material dos homens, com a linguagem da vida real. O representar, o pensar, o intercâmbio espiritual dos homens ainda aparecem, aqui, como emanação direta de seu comportamento material. O mesmo vale para a produção espiritual, tal como ela se apresenta na linguagem da política, das leis, da moral, da religião, da metafísica etc. de um povo. Os 
homens são os produtores de suas representações, de suas ideias e assim por diante, mas os homens reais, ativos, tal como são condicionados por um determinado desenvolvimento de suas forças produtivas e pelo intercâmbio que a ela corresponde, até chegar às suas formações mais desenvolvidas. A consciência [Bewusstsein] não pode jamais ser outra coisa do que o ser consciente [bewusste Sein], e o ser dos homens é o seu processo de vida real (MARX; ENGELS, 2007, p. 94).

Em conexão com a apreensão da produção e do intercâmbio material, precisamos identificar os complexos ideológicos específicos que emergem a partir das requisições postas pelo rol sempre crescente de necessidades humano-sociais para o desenvolvimento do metabolismo social e que atuam ativamente para viabilizar a continuidade ou incidir na superação das formações sociais. A relação intrínseca entre estrutura social e intervenção humana na história é sintetizada nos seguintes termos: "as circunstâncias fazem os homens, assim como os homens fazem as circunstâncias" (MARX; ENGELS, 2007, p. 43). Em sua obra da maturidade, Lukács (2012) identifica que o cerne estruturador do pensamento econômico de Marx se funda na concepção de determinação recíproca das categorias que compõem o complexo do ser social. Afirma o marxista húngaro:

Esse método dialético peculiar, paradoxal, raramente compreendido, repousa na já referida convicção de Marx, de que no ser social, o econômico e o extraeconômico convertem-se continuamente um no outro, estão numa irrevogável relação recíproca, da qual porém não deriva, como mostramos, nem um desenvolvimento histórico singular sem leis, nem uma dominação mecânica "por lei” do econômico abstrato puro, mas da qual deriva, ao contrário, aquela orgânica unidade do ser social, na qual cabe às leis da economia precisamente e apenas o papel de momento predominante (LUKÁCS, 2012, p. 310).

De acordo com Mészáros (2008), o próprio conceito de consciência de classe presente na obra marxiana é ininteligível, apartado da visão de "causalidade social" que lhe corresponde. $\mathrm{Na}$ abordagem de Marx, toda conquista humana introduz um 
elemento novo no conjunto complexo de interações que caracteriza a sociedade em qualquer tempo situado. Portanto, o que seria questão "no início", possivelmente, pode não se manter como questão em um estágio posterior do desenvolvimento histórico. A referência às "condições materiais de vida" ocupa uma posição essencial no sistema marxiano, no sentido genético e estrutural, tanto em relação à gênese histórica das formas mais complexas de intercâmbio humano como diante do fato de que as condições materiais constituem a precondição da vida humana estruturalmente necessária em todas as formas concebíveis de sociedade. Todavia, essa determinação, examinada isoladamente, é incapaz de explicar as complexidades do próprio desenvolvimento social. Em verdade, com o evolver histórico das forças produtivas humanas, o papel da consciência e das formas ideológicas se torna cada vez maior, podendo ser colocado a serviço da vida alienada, da mesma forma que pode visualizar a suplantação da alienação (MÉSZÁROS, 2008).

Para alcançarmos as implicações analíticas mais vastas da abordagem marxiana, devemos considerar, portanto, a "multidimensionalidade" de seus conceitos: todas as categorias não estão apenas estruturalmente inter-relacionadas, sendo também cada uma delas concebida como inerentemente histórica (MÉSZÁROS, 2008, 2004). É necessário, portanto, apreender o dinamismo histórico das categorias estruturalmente interligadas, que são partes constituintes de um todo complexo. Destarte, as formas ideológicas, tal como as próprias classes que as elaboram, apenas adquirem significado completo como focos de uma multiplicidade de fenômenos sociais estrutural e dialeticamente interligados em determinação recíproca (MÉSZÁROS, 2008). Essa relação de interação complexa entre as formas ideológicas e a base socioeconômica é evidenciada no Prefácio à Contribuição à crítica da economia política, no qual o autor sintetiza sua posição analítica:

[...] na produção social da própria existência, os homens entram em relações determinadas, necessárias e independentes de sua vontade; essas relações de produção correspondem a um grau determinado de desenvolvimento de suas forças produtivas 
materiais. A totalidade dessas relações de produção compõe a base real sobre a qual se eleva uma superestrutura jurídica e política e à qual correspondem formas sociais determinadas de consciência (MARX, 2008a, p. 45).

Segundo Mészáros (2008), a estrutura econômica da sociedade, assim analisada, não representa uma entidade material bruta, mas um conjunto de relações sociais historicamente situadas, sujeitas a mudanças - mesmo a transformação mais radical proveniente de uma deliberação humana socialmente consciente (socialista). Os termos apresentados acima são, portanto, mais complexos do que recorrentemente se considera. O conjunto dos conceitos articulados não define as formas de consciência social, muito menos as ideias dos indivíduos, em relação direta com a estrutura econômica (ou a base material), o que ocorre pela mediação (elo intermediário) da superestrutura legal e política, à qual essas formas "correspondem" no nível das ideias, sem qualquer relação de identidade com essa superestrutura. Caracterizar uma relação de simples identidade entre a superestrutura legal e política e as formas de consciência social comprometeria toda a concepção marxiana e acarretaria na obliteração do papel ativo da superestrutura, pois a autonomia das ideias vis-à-vis a superestrutura legal e política é uma precondição necessária das primeiras. A produção das formas ideológicas - para além das restrições institucionais imediatas da superestrutura legal e política - opera como um propulsor poderoso sobre a superestrutura, que, por sua vez, afeta dinamicamente as funções materiais da vida social (MÉSZÁROS, 2008). Apenas partindo de tais indicações teórico-metodológicas, podemos determinar - sem qualquer cientificismo economicista ou politicismo voluntarista - o papel específico da ideologia no processo de ajustamentos estruturais necessários às condições cambiantes de dominação, considerando que a reprodução viável destas não pode ocorrer na ausência de uma intervenção ativa de fatores ideológicos orientados para a preservação do ordenamento imperante.

Segundo Gramsci (2011), a abordagem marxiana que conforma a "filosofia da práxis" apreende a unidade dialética,

7 Em sua pesquisa, Coelho (2005, p. 183) afirma que a nominação "filosofia da 
presente na atividade humana, entre ser e consciência, entre objetividade e subjetividade. O comunista italiano buscou assinalar tal unidade através do conceito de bloco histórico: "O homem deve ser concebido como um bloco histórico de elementos puramente subjetivos e individuais e de elementos de massa e objetivos ou materiais, com os quais o indivíduo está em relação ativa" (GRAMSCl, 2011, p. 406). Antes que restituir, no plano da racionalidade, uma unidade metodológica perdida ou inexistente, trata-se de reproduzir, no plano ideal, o movimento concreto, correspondente ao próprio estatuto ontológico da história humana. Tais implicações metodológicas são derivadas das relações objetivas que constituem a práxis social na história. Abordando o complexo das superestruturas em sua interação com o conjunto das relações sociais, Gramsci (2011, p. 251) afirma: "O raciocínio se baseia sobre a necessária reciprocidade entre estrutura e superestrutura (reciprocidade que é precisamente o processo dialético real)". Destarte, vemos que o conceito de "bloco histórico" é tomado de empréstimo para assinalar a atividade humana como síntese de objetividade e subjetividade:

O conceito do valor concreto (histórico) das su-
perestruturas na filosofia da práxis deve ser apro-
fundado, aproximando-o do conceito soreliano de
"bloco histórico". Se os homens adquirem consci-
ência de sua posição social e de seus objetivos no
terreno das superestruturas, isto significa que entre
estrutura e superestrutura existe um nexo necessá-
rio e vital (GRAMSCI, 2011, p. 389).

A afirmação do "nexo necessário e vital" não elide o momento da "não identidade" entre o complexo socioeconômico e as formas ideológicas. Se a unidade orgânica significasse uma identidade homogênea, a distinção mesma seria supérflua, assim como a determinação das mediações sociais que vinculam tais dimensões. As relações de determinação recíproca entre

práxis" - formulada originalmente por Antônio Labriola - pode assumir dois sentidos heurísticos não excludentes: "Da práxis pode significar uma filosofia que se ocupa da práxis, que a toma por seu objeto. Corresponde, portanto, à noção de 'consciência da própria ação' ou autoconsciência crítica. Mas pode significar também uma filosofia advinda da práxis, engendrada pela própria práxis histórica do proletariado". 
aqueles complexos da atividade humana são enfatizadas por Gramsci como procedimentos fecundos e originais da perspectiva marxiana, cujo cerne deve ser evidenciado na luta ideológica contra as tendências idealistas e deterministas mecânicas. Na crítica à adulteração crociana do "materialismo histórico", o autor informa que "[...] não é verdade que a filosofia da práxis 'destaque' a estrutura das superestruturas; ao contrário, ela concebe o desenvolvimento das mesmas como intimamente relacionado e necessariamente inter-relativo e recíproco" (GRAMSCI, 2011, p. 369). Em suma, a prioridade ontológica da realidade em relação à teoria social, que resulta da atividade teórica - conforme podemos evidenciar como premissa na segunda das "Teses de Feuerbach” (MARX; ENGELS, 2007, p. 533) -, desautoriza, em Marx, qualquer procedimento formal-abstrato para o percurso metodológico assumido. À atividade teórica cabe reproduzir no plano ideal o movimento concreto do objeto, conformado por relações sociais abrangentes e diversificadas, o que implica a recusa de um apriorismo metodológico de determinação unívoca dos aspectos estritamente materiais sobre a apreensão de relações sociais historicamente determinadas.

A unidade entre ser e consciência social, identificada pela "filosofia da práxis", não se encontra esterilizada das contradições que dinamizam o desenvolvimento histórico classista; para Gramsci (2011), ela mesma é uma "teoria das contradições". Essa filosofia radicalmente nova apreende, no campo das superestruturas, a própria práxis humana socialmente determinada, a atividade humana como síntese de objetividade e subjetividade, conformada pelo mundo socioeconômico, e as lutas ideológicas forjadas pelos interesses antagonistas dos sujeitos de classe. Essa determinação consciente dos interesses contraditórios irreconciliáveis, presentes na estrutura social burguesa - diferente das tendências idealistas, que buscavam uma reconciliação no plano do espírito, ou das tendências mecanicistas, que restringem as transformações sociais ao plano reificador dos "instrumentos técnicos de produção" -, orienta a superação dos antagonismos para a totalidade das relações que consubstanciam a própria atividade humana historicamente dada. 


\section{REFERÊNCIAS}

CHAUÍ, M. O que é Ideologia. São Paulo: Brasiliense, 1980.

COELHO, E. Uma esquerda para o capital: Crise do Marxismo e Mudanças nos Projetos Políticos dos Grupos Dirigentes do PT (1979-1998). Tese (Doutorado em História) - Universidade Federal Fluminense, UFF, 2005.

COUTINHO, C. N. De Rousseau a Gramsci: ensaios de teoria política. São Paulo: Boitempo, 2011.

EAGLETON, T. Ideologia: uma introdução. Tradução de S. Vieira e L. C. Borges. São Paulo: Editora da Universidade Estadual Paulista; Boitempo, 1997.

GRAMSCl, A. Cadernos do cárcere: introdução ao estudo da filosofia e a filosofia de Benedetto Croce. Tradução de Carlos Nelson Coutinho com a colaboração de Luiz Sergio Henriques e Marco Aurélio Nogueira. 5. ed. Rio de Janeiro: Civilização Brasileira, 2011. 1 v.

KONDER, L. A Questão da Ideologia. São Paulo: Cia das Letras, 2002.

LÖWY, M. As aventuras de Karl Marx contra o Barão de Münchhausen. 7. ed. Tradução de Juarez Guimarães e Suzane Felice Léwy. São Paulo: Cortez, 2000.

LUKÁCS, G. Para uma ontologia do ser social I. Tradução de Carlos Nelson Coutinho, Mario Duayer, Nélio Schneider. São Paulo: Boitempo, 2012.

. Prolegômenos para uma ontologia do ser social: questões de princípios para uma ontologia hoje tornada possível. Tradução de Lya Luft e Rodnei Nascimento. São Paulo: Boitempo, 2010.

MARX, K. Grundrisse: manuscritos econômicos de 1857-1858: esboços da crítica da economia política. São Paulo: Boitempo; Rio de Janeiro: Editora da UFRJ, 2011.

- Lutas de Classes na Alemanha. Tradução de Nélio Schneider. São Paulo: Expressão Popular, 2010a. 
. Crítica da filosofia do direito de Hegel. 2. ed. Tradução de Rubens Enderle e Leonardo de Deus. São Paulo: Boitempo, 2010b.

. Contribuição à crítica da economia política. Tradução de Florestan Fernandes. São Paulo: Expressão Popular, 2008a.

- O capital: crítica da economia política - O processo de produção do capital. Tradução de Reginaldo Sant'Anna. Rio de Janeiro: Civilização Brasileira, 2008b.

; ENGELS, F. A ideologia alemã. Tradução de Rubens Enderle, Nélio Schneide e Luciano Cavini Martorano. São Paulo: Boitempo, 2007.

; ENGELS, F. A sagrada família. Tradução de Marcelo Bakes. São Paulo: Boitempo, 2003.

MÉSZÁROS, I. Para além do capital: rumo a uma teoria da transição. São Paulo: Boitempo, 2009.

. Filosofia, ideologia e ciência social. Tradução de Ester Vaisman. São Paulo: Boitempo, 2008.

- O poder da ideologia. Tradução de Paulo Cezar Castanheira. São Paulo: Boitempo, 2004.

ROSDOLSKY, Roman. Gênese e estrutura de O Capital de Karl Marx. Rio de Janeiro: EDUERJ; Contraponto, 2001.

VAISMAN, E. A ideologia e sua determinação ontológica. Verinotio, ano VI, n. 12, p. 40-64, 2010. Disponível em: <http:// www.verinotio.org/conteudo/0.49365 995032122.pdf> Acesso em: 10 jun. 2012.

ZIZEK, S. (Org.). Um mapa da ideologia. Tradução de Vera Ribeiro. Rio de Janeiro: Contraponto, 1996. 